\title{
Global and regional impacts of climate change at different levels of global temperature increase
}

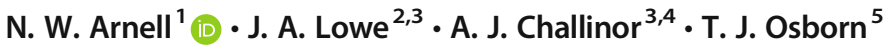 \\ Received: 3 December 2018 / Accepted: 6 May 2019 /Published online: 27 June 2019 \\ (C) The Author(s) 2019
}

\begin{abstract}
The assessment of the impacts of climate change at different levels of global warming helps inform national and international policy discussion around mitigation targets. This paper provides consistent estimates of global and regional impacts and risks at increases in global mean temperature up to $5{ }^{\circ} \mathrm{C}$ above pre-industrial levels, for over 30 indicators representing temperature extremes and heatwaves, hydrological change, floods and droughts and proxies for impacts on crop yields. At the global scale, all the impacts that could plausibly be either adverse or beneficial are adverse, and impacts and risks increase with temperature change. For example, the global average chance of a major heatwave increases from $5 \%$ in $1981-2010$ to $28 \%$ at $1.5{ }^{\circ} \mathrm{C}$ and $92 \%$ at $4{ }^{\circ} \mathrm{C}$, of an agricultural drought increases from 9 to $24 \%$ at $1.5{ }^{\circ} \mathrm{C}$ and $61 \%$ at $4{ }^{\circ} \mathrm{C}$, and of the 50 -year return period river flood increases from 2 to $2.4 \%$ at $1.5{ }^{\circ} \mathrm{C}$ and $5.4 \%$ at $4{ }^{\circ} \mathrm{C}$. The chance of a damaging hot spell for maize increases from 5 to $50 \%$ at $4{ }^{\circ} \mathrm{C}$, whilst the chance for rice rises from 27 to $46 \%$. There is considerable uncertainty around these central estimates, and impacts and risks vary between regions. Some impacts - for example heatwaves - increase rapidly as temperature increases, whilst others show more linear responses. The paper presents estimates of the risk of impacts exceeding specific targets and demonstrates that these estimates are sensitive to the thresholds used.
\end{abstract}

Electronic supplementary material The online version of this article (https://doi.org/10.1007/s10584-01902464-z) contains supplementary material, which is available to authorized users.

\section{N. W. Arnell}

n.w.arnell@ reading.ac.uk

1 Department of Meteorology, University of Reading, Reading, UK

2 Met Office Hadley Centre, Exeter, UK

3 Priestley International Centre for Climate, University of Leeds, Leeds, UK

4 CGIAR Research Program on Climate Change, Agriculture and Food Security (CCAFS), International Centre for Tropical Agriculture (CIAT), Cali, Colombia

5 Climatic Research Unit, School of Environmental Sciences, University of East Anglia, Norwich, UK 


\section{Introduction and context}

Over the last few years, several studies have estimated the global and regional impacts across sectors of climate change under specific scenarios for future emissions and forcings (e.g., Arnell et al. 2016a; O'Neill et al. 2018; Warszawski et al. 2014). However, there is a strong policy demand for evidence on the potential impacts at different levels of change in global mean temperature which do not necessarily correspond to the levels associated with the small number of forcing scenarios that are typically used. This would allow the comparison of impacts under different potential policy targets. The Summary for Policymakers of Working Group 2 for the Fifth Assessment Report of the Intergovernmental Panel on Climate Change (IPCC 2014) presented synthesis diagrams representing impacts at 2 and $4{ }^{\circ} \mathrm{C}$ above preindustrial conditions, but these were based on expert judgement rather than quantitative impact assessments. Similarly, the well-known 'reasons for concern' diagrams (O'Neill et al. 2017) plot impacts against global mean temperature increase, but again, these are based on expert judgement.

Few studies have explicitly compared global and regional impacts at different temperature levels (IPCC 2018). Arnell et al. (2016b) presented 'damage functions' relating impact to change in global mean temperature, using scenarios constructed from CMIP3-generation climate models by pattern-scaling, and Arnell et al. (2018) used a similar approach with CMIP5-generation climate models to assess the impacts avoided if low temperature targets are met. Schleussner et al. (2016), Naumann et al. (2018) and Ostberg et al. (2018) estimated impacts using scenarios representing specific temperature targets constructed by 'time-slicing' (extracting the periods from a climate model simulation with the target mean change in global temperature). Seneviratne et al. (2016) plotted global average temperature and precipitation extreme indices against global mean temperature change, derived from decadal means calculated from CMIP5 model output. Betts et al. (2018) estimated impacts using highresolution climate model simulations forced by sea surface temperature and sea ice patterns corresponding to increases in temperature of 1.5 and $2{ }^{\circ} \mathrm{C}$ above pre-industrial levels but did not consider impacts at higher levels. With the exception of Arnell et al. (2016b, 2018) and Seneviratne et al. (2016), these studies used small subsets of available climate models to construct climate scenarios.

This paper presents global and regional impacts at different levels of increase in global mean temperature for over 30 indicators characterising impacts on heat extremes, water resources, river flooding and agriculture. It builds on Arnell et al. (2016b) by using CMIP5generation climate model patterns and more indicators and extends substantially Arnell et al. (2018) by using a much wider range of indicators and a more recent climate reference period. The paper focuses on changes in the occurrence of physical climate hazards and the natural resource base at different levels of increase in global mean temperature, using indicators that are relevant to socio-economic impacts. Summary results at the global and continental levels are presented in the main part of the paper, and the Supplementary Material provides plots and tables at the regional scale. The results will be of value to those summarising and comparing impacts across sectors at different levels of global warming, for example in the IPCC's Sixth Assessment Report currently in preparation. They provide quantitative evidence to supplement expert judgement as used in the Fifth Assessment Report and to help guide the assessment of impacts at different levels of warming as represented by the 'reasons for concern' framing.

Future socio-economic impacts also depend on changes in exposure and vulnerability, as characterised by socio-economic scenario. These are not considered here, although 
implications for socio-economic impacts are summarised in 'Section 4.' A companion paper (Arnell et al., in review) assesses impacts under specific forcing and socio-economic pathways.

\section{Impact indicators and methodology}

More than 30 impact indicators are calculated at the regional and global scales using spatially explicit impacts models and climate scenarios representing different levels of increase in global mean temperature above pre-industrial levels constructed by pattern-scaling. 'Pre-industrial' is defined as the period 1850 to 1900 .

The impact indicators are summarised in Table 1, and the specific details of their calculation are presented in Supplementary Material 1. Except for the global average temperature, all can be interpreted as proxies for impacts in each sector and are indicators of direct relevance to policy users. The two heatwave frequency indicators represent different magnitudes of heatwave, but do not reflect duration: the heatwave duration indicator characterises the average number of heatwave-days per year, but not the frequency of heatwaves. The hot-humid day indicator (days with a Wet Bulb Globe Temperature greater than $32{ }^{\circ} \mathrm{C}$ ) maps onto human comfort and the capacity to do work. The heat extreme indicators do not account for the effects of urban heat islands on temperatures. The two runoff change indicators (area with increase or decrease in average runoff) relate to pervasive water scarcity, whilst the two hydrological drought indicators characterise drought duration and occurrence. The two river flood indicators represent flood risks to people and cropland. The heating and cooling degree day indicators are proxies for demands for energy for heating and cooling, and the frost day indicator represents the occurrence of cold days. Two indicators of agricultural drought are presented, one based just on precipitation (SPI) and one combining precipitation and evaporation (SPEI): in both cases, indicators characterise the duration and frequency of droughts. Three indicators are calculated for the five key staple crops. The change in average length of the crop growing season is an indicator of potential changes in average yield: yield decreases as the crop growing season reduces because crops develop more quickly. The other two crop indicators - the frequency of hot spells and the frequency of rainfall deficits - characterise changes in the occurrence of extreme events that challenge crop production.

For each sector and risk, many indicators have been presented in previous studies (for example by Russo et al. (2014), Schleussner et al. (2016), Naumann et al. (2018), O’Neill et al. (2018) and Betts et al. (2018)). Different indicators can give different impressions of impact and hinder comparisons between studies.

All the impact models calculate impacts at a spatial resolution of $0.5 \times 0.5^{\circ}$. The runoff change indicators are expressed as regional (Supplementary Material 2), continental and global area totals, but the other indicators are then presented as regional, continental and global averages. The agricultural indicators are weighted by cropland area, and the other indicators (temperature and heat indicators, hydrological drought and 50-year flood indicators) are averaged just over grid cells with a population of more than 1000 people in 2010. This is because the focus here is on the impacts of climate change relevant to people: weighting by population was considered, but not used because relatively few grid cells with high population dominate the regional average.

The period 1981-2010 is used as the baseline climate reference period, as represented by the CRU TS4 climatology (Harris et al. 2014). The global average temperature over this period is $0.61{ }^{\circ} \mathrm{C}$ above pre-industrial levels. 
Table 1 Summary of the regional proxy impact indicators

Indicator Description

\section{Increase in average annual temperature \\ Heat extremes \\ Heatwave frequency \\ Major heatwave
frequency}

Heatwave duration

Hot-humid days

Frost days

Energy demand

Cooling degree days

Heating degree days

Water resources

Area with decrease/ increase in runoff

Hydrological drought time

Hydrological drought frequency

River flooding

Frequency of current 50-year flood

Frequency of current 30-year flood

Agriculture

Agricultural drought time (SPI)

Agricultural drought frequency (SPI)

Agricultural drought time (SPEI)

Agricultural drought frequency (SPEI)

Reduction in crop growth duration (maize, winter wheat, spring wheat, soybean and rice)

Hot spell frequency (maize, winter wheat, spring wheat, soybean and rice)
Regional average increase in temperature. Averaged over cells with more than 1000 people in 2010

Likelihood (\%) that a year will contain a heatwave, with maximum temperature greater than the 98th percentile of the warm season temperatures for at least two days. Averaged over cells with more than 1000 people in 2010

Likelihood (\%) that a year will contain a heatwave, with maximum temperature greater than the 99th percentile of the warm season temperatures for at least 4 days. Averaged over cells with more than 1000 people in 2010

Average annual number of days in a heatwave (as defined above). Averaged over cells with more than 1000 people in 2010

Average annual number of days with Wet Bulb Globe Temperature greater than $32{ }^{\circ} \mathrm{C}$. Averaged over cells with more than 1000 people in 2010

Average annual number of days with minimum temperature less than $0{ }^{\circ} \mathrm{C}$. Averaged over cells with more than 1000 people in 2010

Cooling degree days, using a threshold of $18{ }^{\circ} \mathrm{C}$. Averaged over cells with more than 1000 people in 2010

Heating degree days, using a threshold of $18^{\circ} \mathrm{C}$. Averaged over cells with more than 1000 people in 2010

$\%$ of region with a decrease/increase in average annual runoff more than twice the standard deviation of 30-year average runoff

Proportion of time spent in hydrological drought (Standardised Runoff Index: Shukla and Wood 2008). Averaged over cells with more than 1000 people in 2010

Likelihood (\%) that a year will contain a hydrological drought, lasting for at least six consecutive months. Averaged over cells with more than 1000 people in 2010

Likelihood (\%) that a year will contain a flood greater than the reference period 50 -year flood (2\% likelihood). Averaged over cells with more than 1000 people in 2010

Likelihood (\%) that a year will contain a flood greater than the reference period 30 -year flood (3.33\% likelihood). Weighted by cropland area

Proportion of time spent in agricultural drought (defined by Standardised Precipitation Index: McKee et al. 1983). Weighted by cropland area

Likelihood (\%) that a year will contain an agricultural drought (SPI), lasting for at least three consecutive months. Weighted by cropland area

Proportion of time spent in agricultural drought (defined by Standardised Precipitation Evaporation Index: Vicente-Serrano et al. 2010). Weighted by cropland area

Likelihood (\%) that a year will contain an agricultural drought (SPEI), lasting for at least three consecutive months. Weighted by cropland area

Average annual change in crop growth duration. Crop growth duration is based on the time taken to accumulate the reference period average growing season accumulated thermal time (ATT: Challinor et al. 2016). Weighted by maize, winter wheat, spring wheat, soybean and rice area

Likelihood (\%) that a year will contain a damaging hot spell, defined as at least 5 days during the 30 -day reproductive phase with temperatures above a threshold: maize $36{ }^{\circ} \mathrm{C}$, wheat $34{ }^{\circ} \mathrm{C}$, soybean $39{ }^{\circ} \mathrm{C}$ and rice $36{ }^{\circ} \mathrm{C}$ (thresholds from Challinor et al. 2016 and Lou 2011). Weighted by maize, winter wheat, spring wheat, soybean and rice area 
Table 1 (continued)

\begin{tabular}{|c|c|}
\hline Indicator & Description \\
\hline $\begin{array}{l}\text { Reduction in growing } \\
\text { season rainfall } \\
\text { (maize, } \\
\text { winter wheat, spring } \\
\text { wheat, soybean and } \\
\text { rice) }\end{array}$ & $\begin{array}{l}\text { Likelihood }(\%) \text { that growing season rainfall is less than the standard deviation of } \\
\text { growing season rainfall. Weighted by maize, winter wheat, spring wheat, } \\
\text { soybean and rice area }\end{array}$ \\
\hline
\end{tabular}

Climate scenarios representing changes in climate at different levels of increase in global mean temperature are constructed using pattern-scaling (Osborn et al. 2016) from 23 CMIP5 climate models (Supplementary Material 3). This produces 23 scenarios for a given increase in temperature. Model changes in mean monthly climate variables from a model reference period are first downscaled statistically to the $0.5 \times 0.5^{\circ}$ resolution, and changes per degree increase in global mean temperature are determined by fitting linear regressions for each grid cell, month and variable. These scaled patterns are then rescaled to represent changes corresponding to specific increases in global mean temperature (between 0.25 and $6{ }^{\circ} \mathrm{C}$ above the reference period). The changes are then applied to the 1981-2010 reference climatology using the delta method to produce 30 -year monthly time series at each grid cell representing specific temperature increases. Monthly climate data are disaggregated to the daily time scale (Supplementary Material 1). The climate scenarios characterise mean monthly temperature, precipitation, wet days, vapour pressure and cloud cover (from which net radiation is calculated), and the variability from year to year in monthly precipitation. Wind speed (used in the calculation of potential evaporation, and therefore SPEI and the indicators based on runoff) is assumed not to change. It is assumed that all 23 climate model patterns are equally plausible and represent the full range in possible regional changes in climate: this is of course not necessarily the case.

Pattern-scaling makes several assumptions (Osborn et al. 2016, 2018), including that climate change occurs linearly at each grid cell and that the spatial pattern of change does not depend on the rate of change in climate. Both are reasonable assumptions (Osborn et al. 2018). Another approach to constructing scenarios representing specific increases in temperature is to extract data from periods in a climate model run corresponding to the defined change in global temperature (time-slicing: James et al. 2017). This uses climate model output directly (often after bias correction), but the differences between time slices and therefore temperature increments are due not only to underlying climate change but also interannual variability in climate. This is particularly significant for precipitation and therefore impacts driven by changes in precipitation. Pattern-scaled scenarios smooth out the effects of interannual variability. The use of large ensembles of individual climate models (as in BRACE: O'Neill et al. 2017) would also smooth out interannual variability, but such large ensembles are available for very few climate models.

\section{Global and regional impacts}

Figure 1 shows global-scale impacts at different increases in global mean temperature above pre-industrial levels. Table 2 shows the median estimate of impacts at 1.5, 2 and 
$4{ }^{\circ} \mathrm{C}$ from the 23 models together with the lowest and highest values, and Fig. 2 summarises global impacts across the indicators. Figure 3 shows the chance that impacts exceed specific thresholds, assuming that all 23 model patterns are equally plausible and are representative of the range in possible patterns. Figure 4 shows impacts at 1.5, 2 and $4{ }^{\circ} \mathrm{C}$ above pre-industrial levels for each indicator by continent (similar plots showing impacts by region are shown in Supplementary Material 4, along with plots summarising all the indicators for each region).

At the global scale, almost all the impacts that could be either adverse or beneficial become worse as global mean temperature increases. Floods, droughts, heatwaves and hot spells all become more frequent, and crop growth duration reduces. The risk of lower growing season rainfall increases for maize, winter wheat and rice under all climate model patterns, but the picture is more mixed for soybean and spring wheat. The frequency of cold spells and accumulated heating degree days reduces. Increasing global mean temperature has a greater relative effect on the frequency of major heatwaves than smaller heatwaves, and the different crops are differently sensitive to hot spells as temperature rises.

\section{Global}
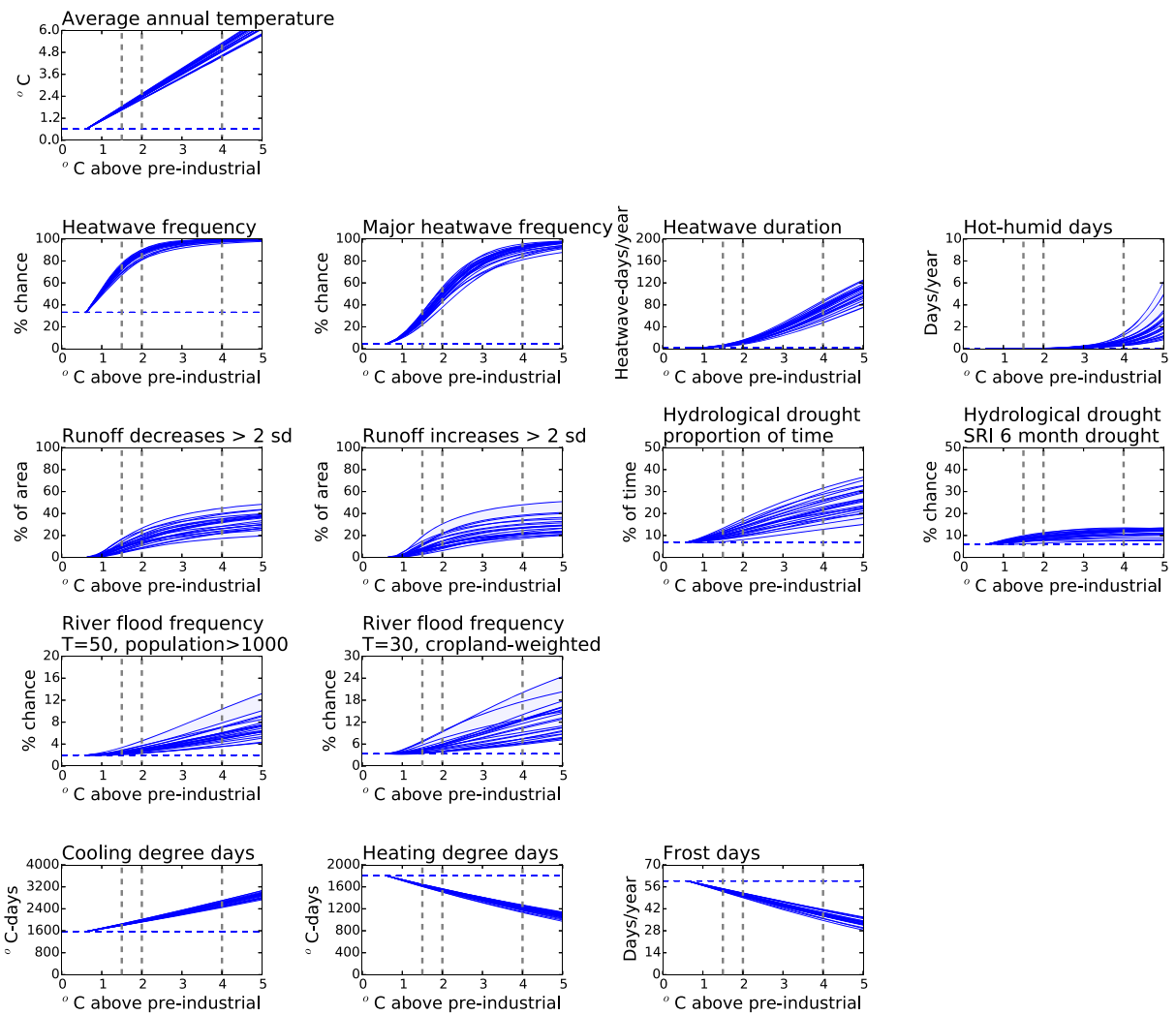

Fig. 1 Impacts at different levels of increase in global mean temperature above pre-industrial levels: the global scale. The horizontal dotted line shows the impacts with the 1981-2010 climate, and the vertical dotted lines show 1.5, 2 and $4{ }^{\circ} \mathrm{C}$ above pre-industrial levels. The individual lines show the 23 climate model patterns 
Global

b
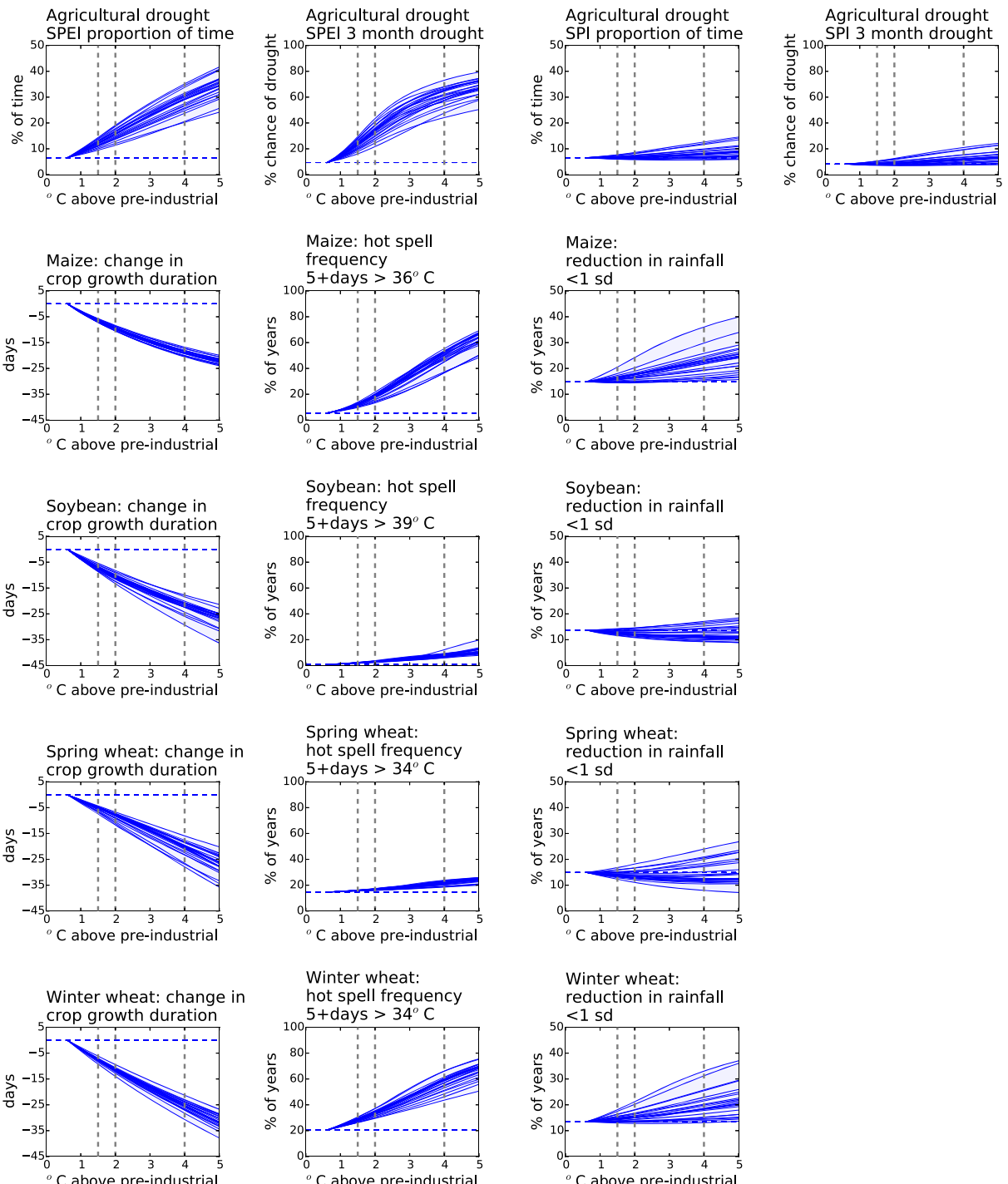

First rice: change in
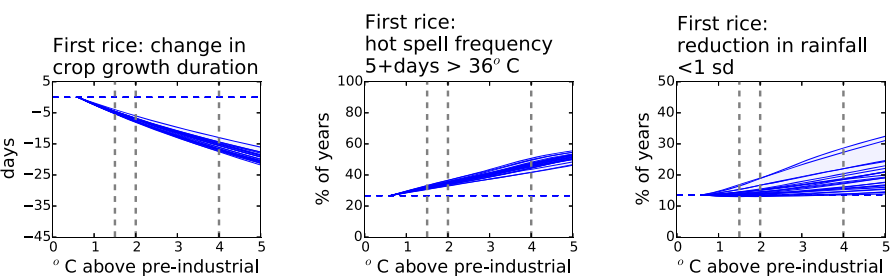

Fig. 1 (continued)

The shape of the relationship between change in global mean temperature and impact varies between indicators, as was found in previous studies (Arnell et al. 2016b). For some of the 


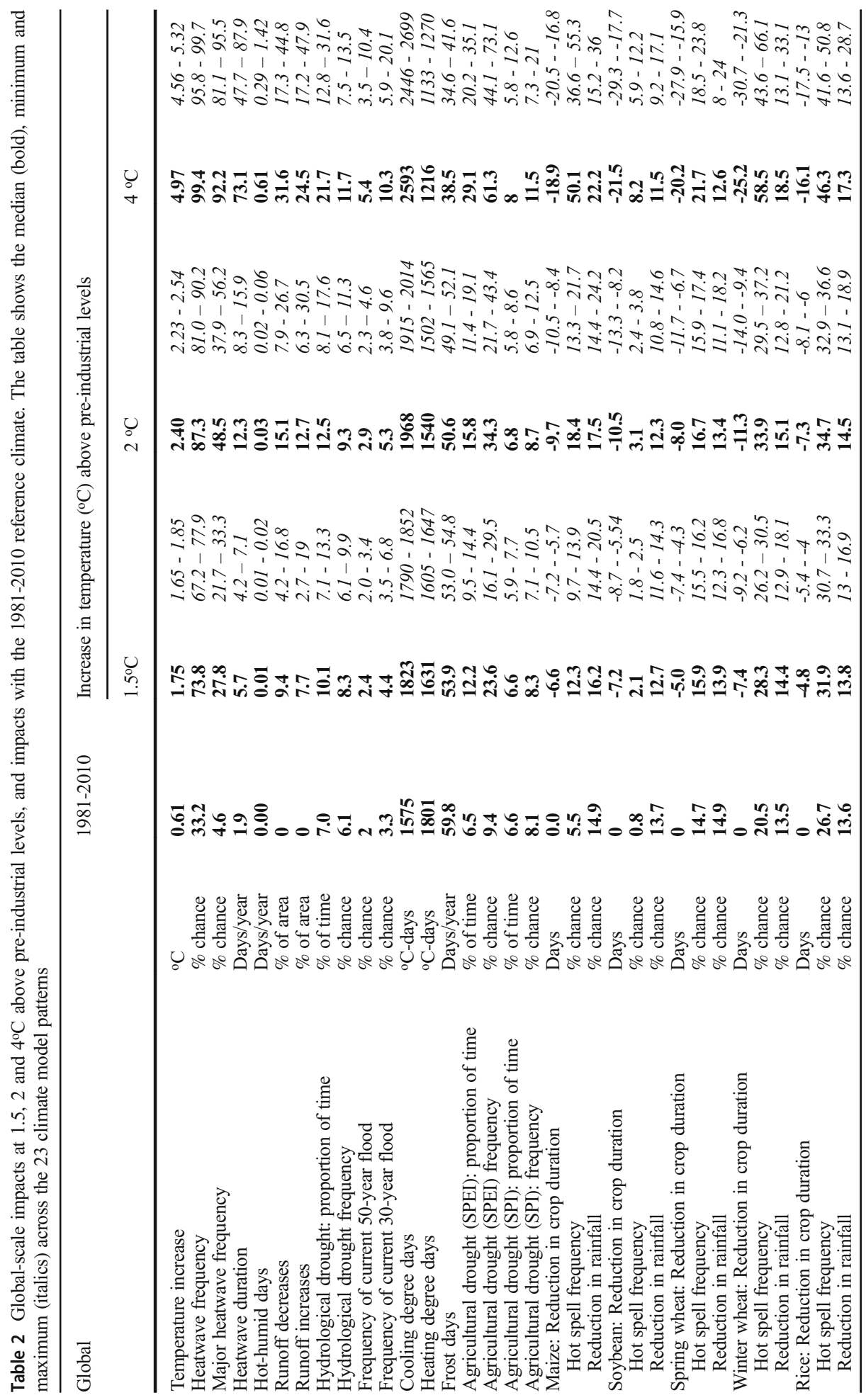




\section{Global}

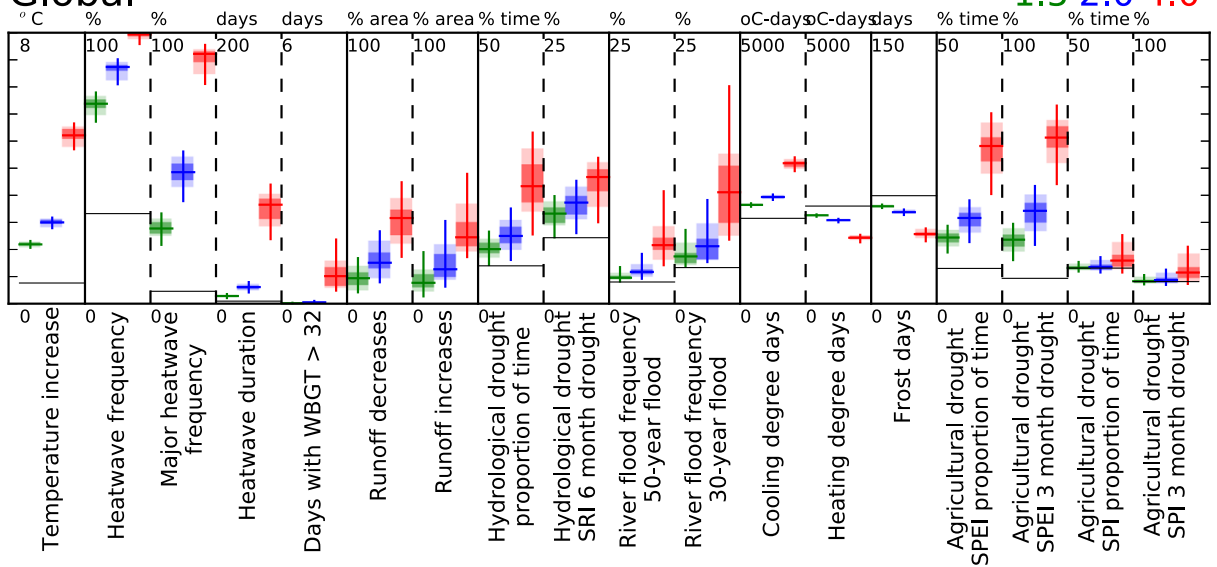

\section{Global}

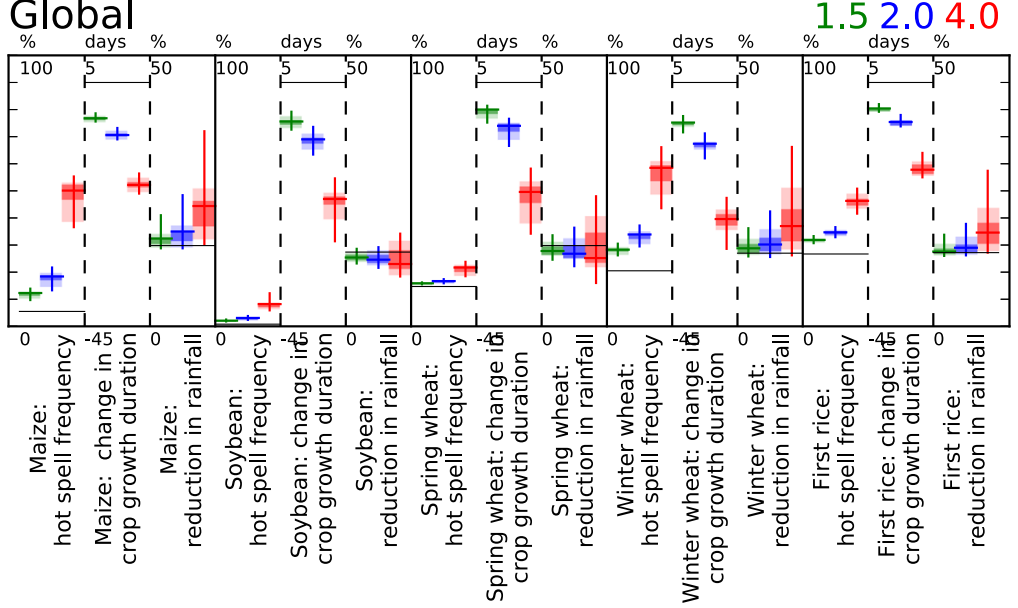

Fig. 2 Summary of the global-scale impacts across the indicators, at $1.5,2$ and $4{ }^{\circ} \mathrm{C}$ above pre-industrial levels. The horizontal coloured lines show the median impact, the dark shading shows the inter-quartile range and the light shading shows the 10th to 90th percentile range. The vertical lines show the range between lowest and highest impact

indicators, the relationship is effectively linear (e.g. cooling and heating degree days and some of the agricultural drought indicators and crop hot spell indicators). Some relationships increase to a specific change in global mean temperature, and then the rate of increase declines. For the heatwave frequency indicator, this is because once the increase in global mean temperature reaches a certain value (approximately $3{ }^{\circ} \mathrm{C}$ ) then at least one heatwave is likely each year. For the runoff change indicator, this is because the area which can be exposed to a reduction (or increase) in runoff is constrained by the spatial variability of change in precipitation. Once all the areas with an increase in precipitation sees a 'significant' increase in runoff, for example, the area can increase no more. 
Most of the indicators show increases in impacts at small increases in temperature, in particular those characterising the frequency of heatwaves and hot spells (for most of the crops considered), and crop growth duration. The hot-humid day indicator shows little impact at the global scale until the temperature increase exceeds $3{ }^{\circ} \mathrm{C}$.

For the indicators which are influenced by changes in precipitation, there is both a very large spread in the estimated impacts at a specific increase in temperature and a variety in the shape of the relationship between temperature increase and impact. The distribution of impacts at a given increase in temperature across the 23 model patterns is not necessarily unimodal. This may reflect sampling biases in the 23 models (which are of course not completely independent), or fundamental differences in the projected spatial patterns of climate change between climate models. The difference in projected impacts on agricultural drought between the SPI and SPEI indicators demonstrates the importance of changes in evaporative demands for future agricultural drought risk. In some regions (including much of Africa and Asia, Eastern Europe and Canada), SPI drought duration and likelihood are projected to reduce under some of the 23 patterns, but SPEI drought duration and likelihood increase everywhere under all patterns. The uncertainty range is also considerably smaller with the SPI drought

Global

a
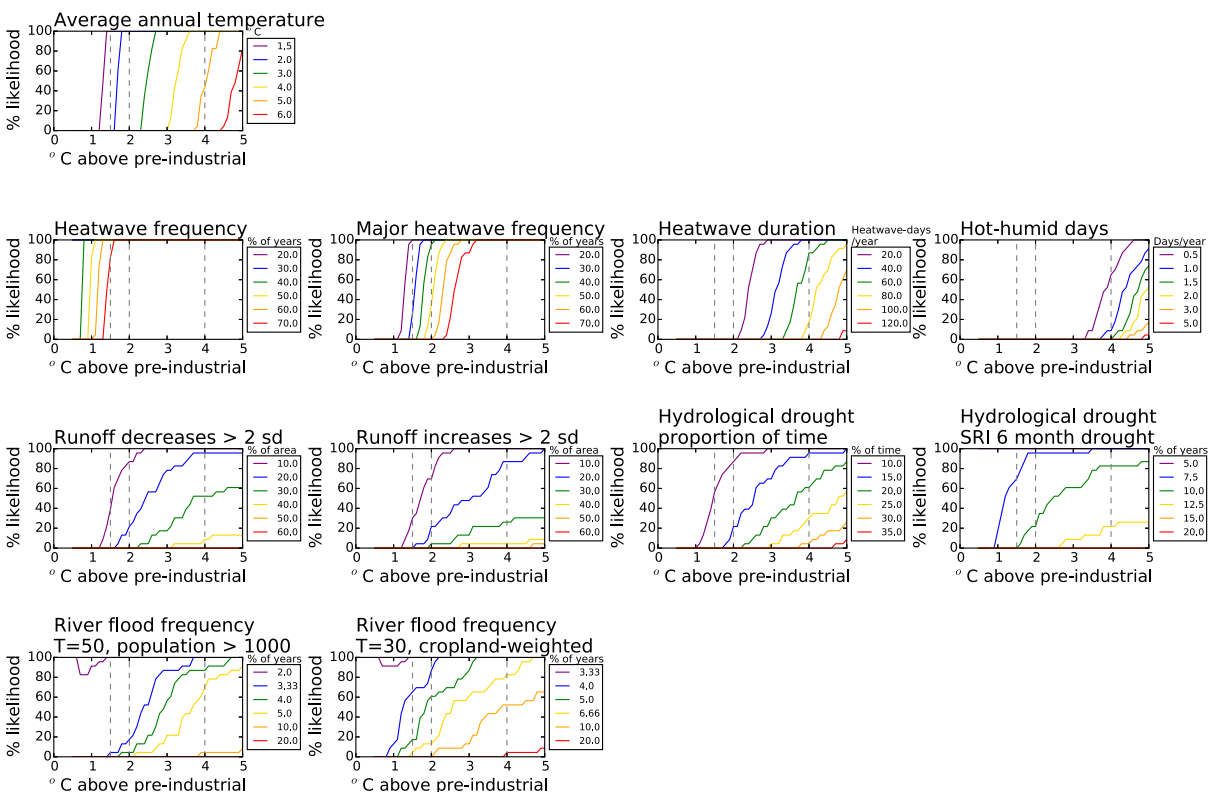

$$
\text { River flood frequency }
$$
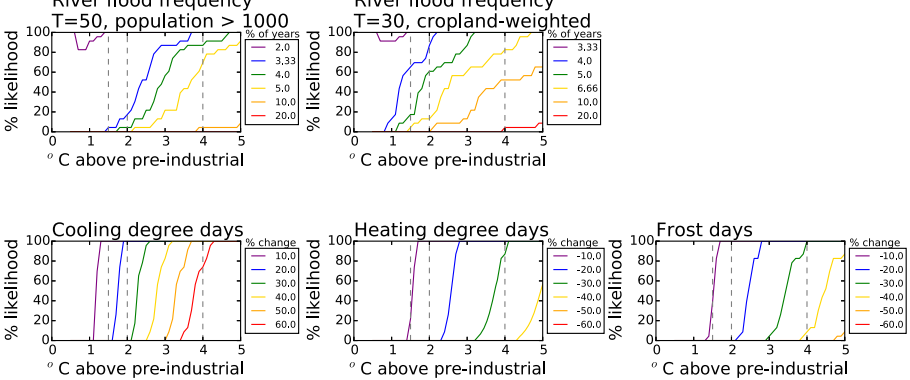

Fig. 3 The chance that impacts exceed specified thresholds at different levels of increase in global mean temperature above pre-industrial levels: the global scale. The thresholds are shown in each panel. The vertical dotted lines show $1.5,2$ and $4{ }^{\circ} \mathrm{C}$ above pre-industrial levels 

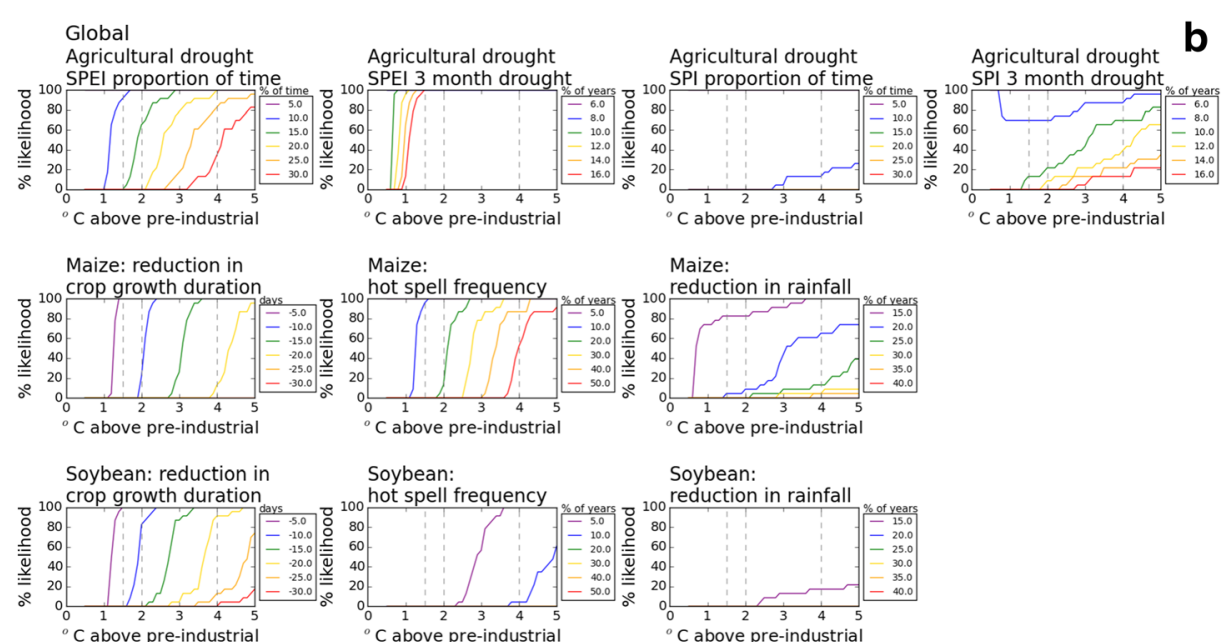

Soybean:
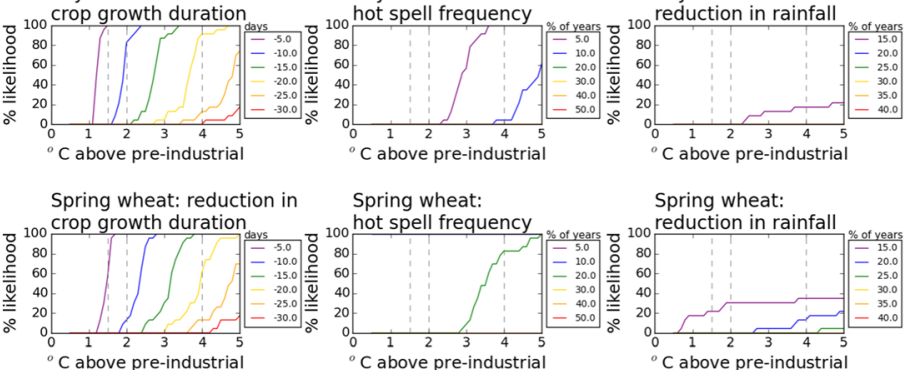

Spring wheat:
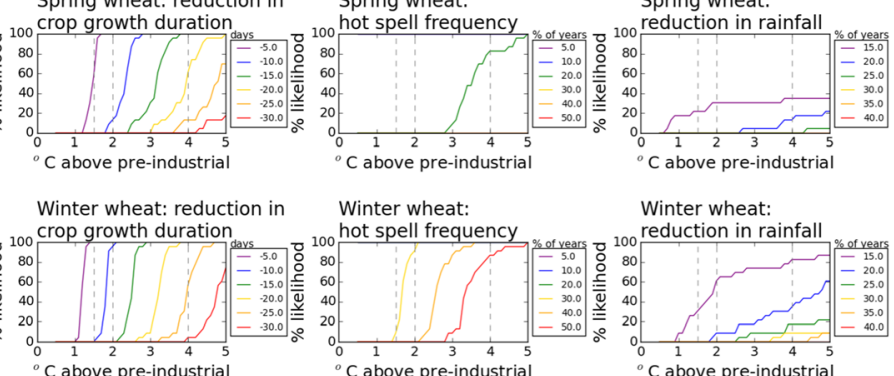

Winter wheat:

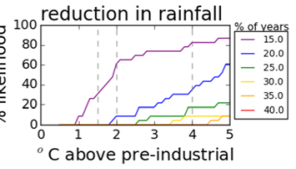

First rice: reduction in

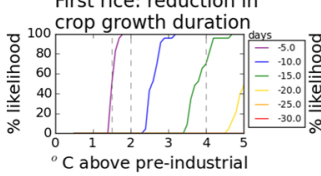

First rice:
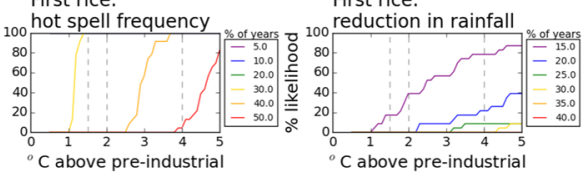

Fig. 3 (continued)

indicator than with SPEI. This is because SPEI is effectively the difference between two uncertain values (precipitation and evaporation).

The global plots of the chance of impacts exceeding different thresholds (Fig. 3) illustrate the obvious point that the chance depends strongly on threshold. The gradients of the risk curves reflect the range between the 23 climate model patterns. The steepest curves occur where the range between the models is small, for example, with the heatwave frequency, heating/cooling and crop duration indicators. In a few cases for some thresholds, the chance of an impact decreases at first and then increases as global temperature increases further (e.g. the flood and SPI frequency indicators). This arises because some of the damage functions for these indicators show a reduction then an increase in impact, which typically occurs because increases in the magnitude of impacts in one place begin to exceed reductions in others (at the point scale, this shape may arise because of local non-linear relationships between force and response). 
The regional plots (Fig. 4) show the regional variation in the magnitude of impact and the relationship between impacts at different levels of temperature increase. For most of the indicators, variability between regions is considerably greater at $4{ }^{\circ} \mathrm{C}$ than at 1.5 or $2{ }^{\circ} \mathrm{C}$, suggesting increased regional variability in impact at higher levels of warming. Some of the indicators show very strong regional concentrations of impact. For example, the increase in hot-humid days is concentrated in Asia (and particularly South Asia) and parts of Africa, and hot spells damaging to spring wheat remain very rare in Europe and North America even with $4{ }^{\circ} \mathrm{C}$ of warming.

The global and regional plots show the ranges in impacts across the 23 model patterns, without distinguishing between the individual models. The relationships between impacts in different places and across sectors are therefore not apparent. In practice, this means that it cannot be assumed that the maximum impact at, say, $4{ }^{\circ} \mathrm{C}$ will occur simultaneously for all regions and indicators: the aggregate 'worst case' is not equal to the sum of the individual regional and sector worst cases.
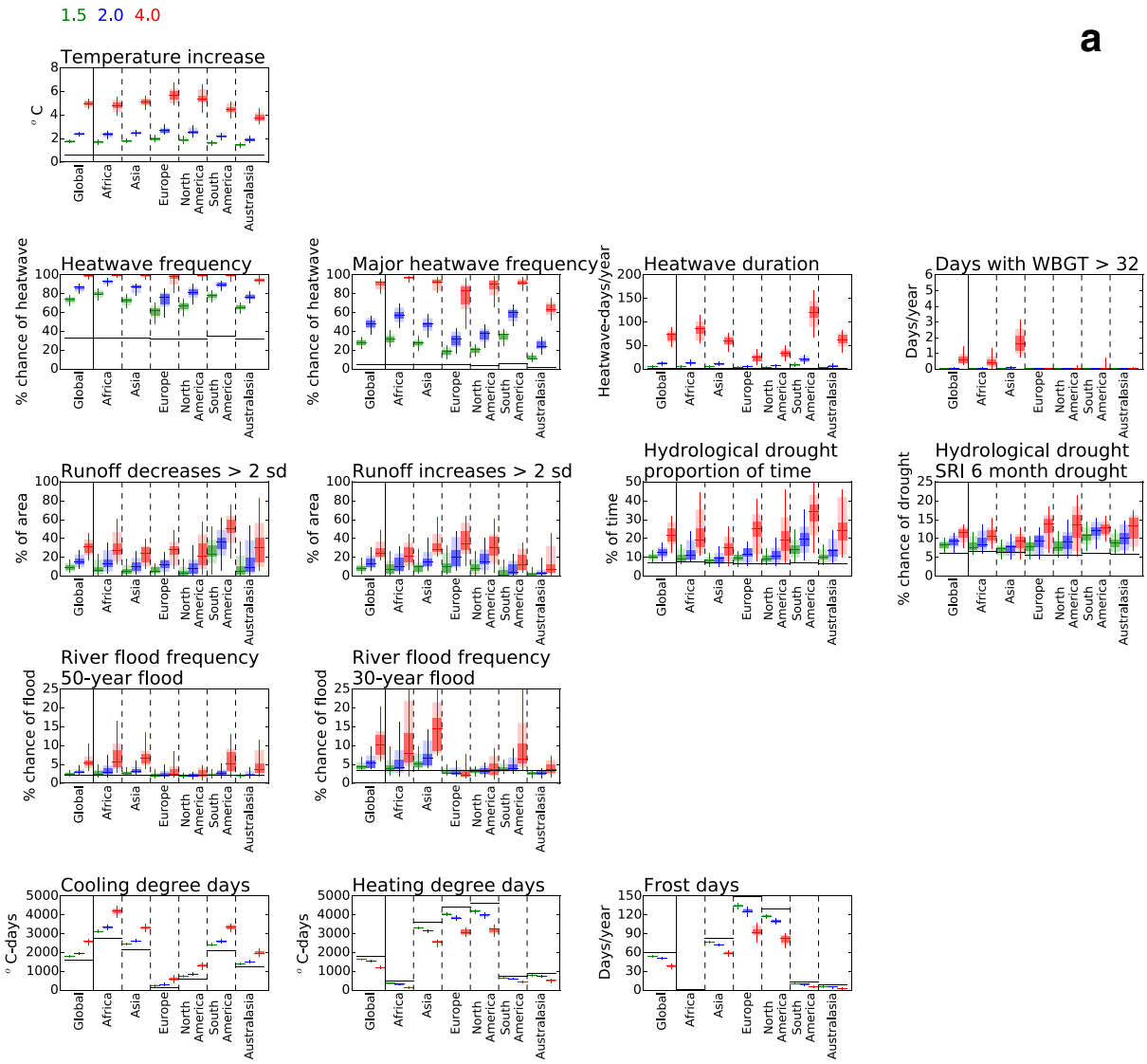

Fig. 4 Impacts at $1.5,2$ and $4{ }^{\circ} \mathrm{C}$ above pre-industrial levels: the continental scale. The horizontal black lines show impacts with the 1981-2010 climate. The horizontal coloured lines show the median impact, the dark shading shows the inter-quartile range and the light shading shows the 10th to 90th percentile range. The vertical lines show the range between lowest and highest impact 

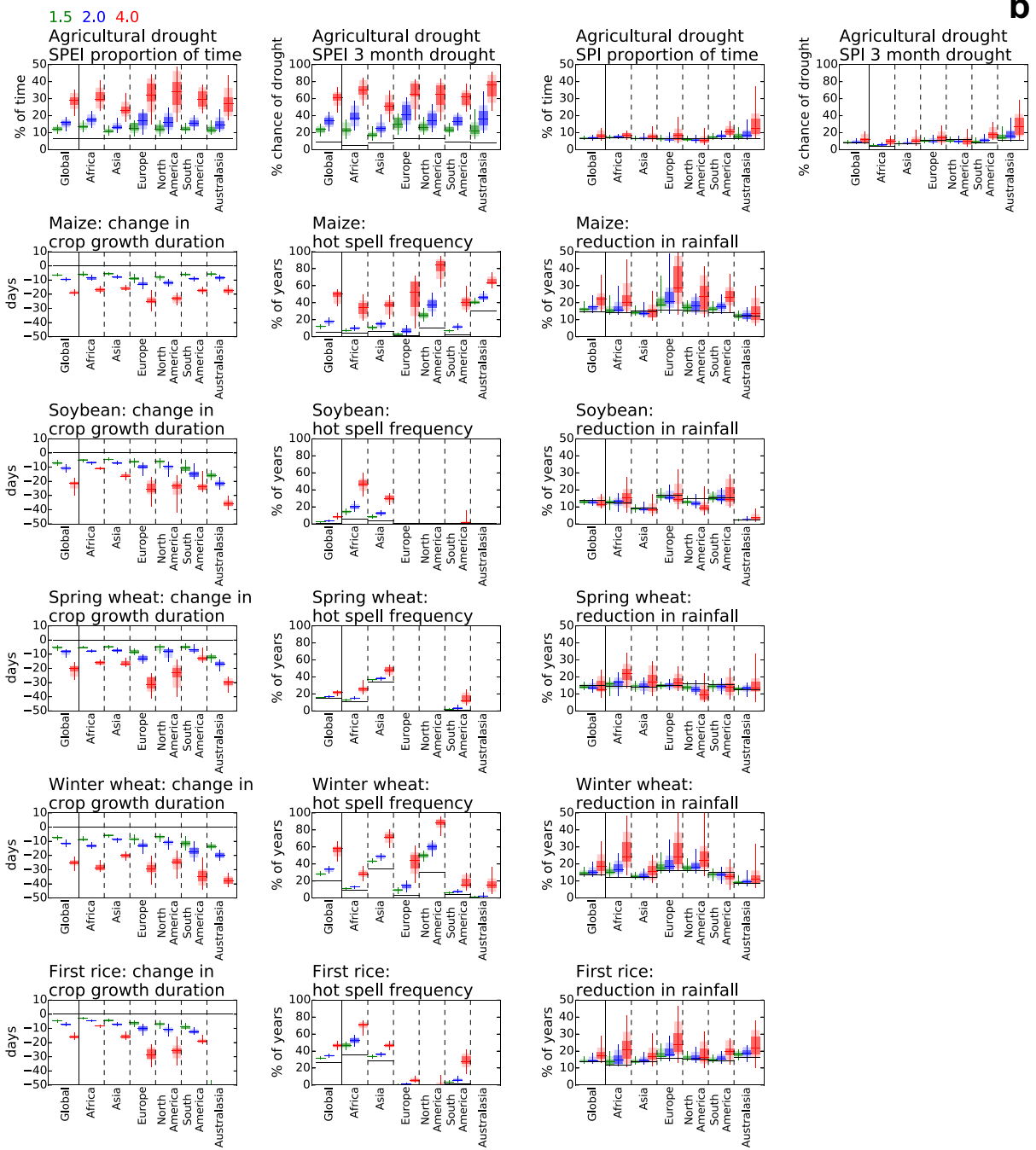

Fig. 4 (continued)

\section{Conclusions}

This paper has presented in graphs and tables (including in Supplementary Material) the global and regional impacts of climate change at different levels of increase in global mean temperature, focusing on impacts at $1.5,2$ and $4{ }^{\circ} \mathrm{C}$ above pre-industrial levels. It uses a large number of climate models to characterise uncertainty in the projected risks and impacts. Other studies have presented global-scale assessments for some of the sectors - using different indicators — but this study uses a consistent approach for indicators across sectors and the same set of climate projections for all indicators, and therefore allows a multi-sectoral assessment of the impacts of climate change at different levels of warming.

There are, of course, several caveats. The relationships between global mean temperature change and impact are constructed using the delta method applied with pattern-scaled output 
from a relatively small number of climate models, which are not necessarily fully independent. Pattern-scaling makes plausible assumptions about the shape of the relationship between climate forcing and climate response, but does not capture potential shifts in local climate regime. The analysis is based on more climate models and hence patterns of climate change than previous studies, but these may still not fully represent the potential range in regional changes. The delta method makes assumptions about changes in interannual variability and downscaling from the monthly to the daily time scale. For many of the impact areas considered here, there are other potential impact indicators (for example based on different definitions of heatwave or different temperature thresholds for agricultural impact), and for some, there are other feasible impact models (for example other hydrological models). Only one impact model is used to calculate each indicator, so the full uncertainty range may be underestimated. For some indicators, the actual quantitative results are sensitive to the weighting method used, although the relative differences between warming levels are more consistent. The approach used here is not suitable for indicators that are dependent on the evolution of climate over time or the rate at which temperature changes (such as ecosystem change), because it essentially uses snapshots representing climate at different levels of warming. An extra complication is added when impacts at a given temperature depend on some other driver-such as level of $\mathrm{CO}_{2}$ - but this can be addressed using damage functions conditional on that driver. Finally, the indicators characterise just changes in physical resource or hazard. Direct socio-economic impacts will depend on future changes in exposure and vulnerability. As a first approximation, direct average annual impacts in terms of numbers of people or extent of cropland affected can be estimated by multiplying the hazard by exposure.

The results of this assessment show the diversity in impacts between indicators, and the different relationships between impacts at different levels in different places and sectors. The study provides regional information that is directly relevant to the IPCC Sixth Assessment Report, providing consistent information using the same indicators across regions for different levels of warming.

At the global scale, all the impacts that could plausibly be either adverse or beneficial are adverse, and the impacts of floods, droughts and heatwaves increase with global mean temperature. Uncertainty in impact at a given temperature level varies between regions. However, the estimated distributions of impacts for a given indicator and increase in temperature across climate model patterns are not necessarily unimodal. This implies first that representing these by the mean or median might be misleading and second that using a subset of climate models could give a misleading impression of the range in potential changes. This paper has for the first time brought together in a consistent way impacts across sectors and regions, estimated from a large number of climate model patterns, and therefore will be valuable to global and regional risk assessments comparing impacts at different levels.

Acknowledgements This work develops from research funded through the UK AVOID2 programme (UK Department for Business, Enterprise and Industrial Strategy grant 1104872). TJO acknowledges the support provided by the EU HELIX project (grant number 603864) for incorporating the CMIP5 climate model patterns into ClimGEN

Open Access This article is distributed under the terms of the Creative Commons Attribution 4.0 International License (http://creativecommons.org/licenses/by/4.0/), which permits unrestricted use, distribution, and reproduction in any medium, provided you give appropriate credit to the original author(s) and the source, provide a link to the Creative Commons license, and indicate if changes were made. 


\section{References}

Arnell NW et al (2016a) The impacts of climate change across the globe: a multi-sectoral assessment. Clim Chang 134:457-474

Arnell NW et al (2016b) Global-scale climate impact functions: the relationship between climate forcing and impact. Clim Chang 134:475-487

Arnell NW et al (2018) The impacts avoided with a $1.5^{\circ} \mathrm{C}$ climate target: a global and regional assessment. Clim Chang 147:61-76

Betts R et al (2018) Changes in climate extremes, fresh water availability and vulnerability to food insecurity projected at $1.5^{\circ} \mathrm{C}$ and $2^{\circ} \mathrm{C}$ global warming with a higher-resolution global climate model. Phil Trans Roy Soc A. https://doi.org/10.1098/rsta.2016.0452

Challinor AJ et al (2016) Current warming will reduce yields unless maize breeding and seed systems adapt immediately. Nat Clim Chang 6:954-958

Harris I et al (2014) Updated high-resolution grids of monthly climatic observations - the CRU TS3.10 dataset. Int J Climatol 34:623-642

IPCC (2014) Summary for policymakers. In: Climate Change 2014: Impacts, Adaptation, and Vulnerability. Part A: Global and Sectoral Aspects. Contribution of Working Group II to the Fifth Assessment Report of the Intergovernmental Panel on Climate Change [Field, C.B. et al. (eds.)]. Cambridge University Press, Cambridge, United Kingdom and New York, NY, USA, pp. 1-32

IPCC (2018) Global warming of $1.5^{\circ} \mathrm{C}$. Special Report, Intergovernmental Panel on Climate Change

James R et al (2017) Characterizing half-a-degree difference: a review of methods for identifying regional climate responses to global warming. WIREs Clim Change 8:e457. https://doi.org/10.1002/wcc.457

Luo Q (2011) Temperature thresholds and crop production: a review. Clim Chang 109:583-598

McKee T.B. et al. (1993) The relationship of drought frequency and duration to time scales. in Proceedings of the 8th Conference on Applied Climatology, American Meteorological Society: Boston, MA, Anaheim, CA, pp. 179-184

Naumann G et al (2018) Global changes in drought conditions under different levels of warming. Geophys Res Lett. https://doi.org/10.1002/2017GL076521

O’Neill BC et al (2017) IPCC reasons for concern regarding climate change risks. Nat Clim Chang 7:28-37

O'Neill BC et al (2018) The Benefits of Reduced Anthropogenic Climate ChangE (BRACE): a synthesis. Clim Chang 146:287-301

Osborn TJ et al (2016) Pattern-scaling using ClimGen: monthly-resolution future climate scenarios including changes in the variability of precipitation. Clim Chang 134:353-369

Osborn TJ et al (2018) Performance of pattern-scaled climate projections under high-end warming, part 1: surface air temperature over land. J Clim. https://doi.org/10.1175/JCLI-D-17-0780.1

Ostberg S et al (2018) Changes in crop yields and their variability at different levels of global warming. Earth System Dynamics 9:479-496

Russo S et al (2014) Magnitude of extreme heat waves in present climate and their projection in a warming world. J Geophys Res-Atmos 119(22):12-500

Schleussner C-F et al (2016) Differential climate impacts for policy-relevant limits to global warming: the case of $1.5^{\circ} \mathrm{C}$ and $2^{\circ} \mathrm{C}$. Earth Syst Dyn 7:325-351

Seneviratne S et al (2016) Allowable CO2 emissions based on regional and impact-related climate targets. Nature $529: 477-483$

Shukla S, Wood AW (2008) Use of a standardized runoff index for characterizing hydrologic drought. Geophys Res Lett 35. https://doi.org/10.1029/2007GL032487

Vicente-Serrano SM et al (2010) A multi-scalar drought index sensitive to global warming: the standardised precipitation evapotranspiration index - SPEI. J Clim 23:1696-1711

Warszawski L et al (2014) The Inter-Sectoral Impact Model Intercomparison Project (ISI-MIP): project framework. Proc Natl Acad Sci 111:3228-3232

Publisher's note Springer Nature remains neutral with regard to jurisdictional claims in published maps and institutional affiliations. 